\title{
Bayesian Regression Analysis of Correlates of Modern Contraceptive Method Usage: A Case Study in Hawassa City, Ethiopia
}

\section{Gebreselassie Habtamu Kiros*}

Haramaya University, Haramaya, Ethiopia

\begin{abstract}
Despite widespread adoption of family planning in the developing world contraceptive use is still very low in sub-Saharan Africa including Ethiopia and in other regions. The general objective of this study was identifying the socioeconomic factors of modern contraceptive methods usage among married women of reproductive ages (15-49 years old) in Hawassa city. From a total 990 sampled married women about $57.9 \%$ (573) were modern contraception methods users. Bayesian logistic regression procedure was adopted to make inference about the parameters of a logistic regression model. The purpose of this method is generating the posterior distribution of the unknown parameters given both the data and some prior density for the unknown parameters. Bayesian inference for logistic regression models is derived applying a Markov Chain Monte Carlo algorithm to simulate from the joint posterior distribution of the regression and the link parameters.
\end{abstract}

Keywords: Family planning; Logistic regression; Markov chain Monte Carlo; Posterior distribution; Prior density

\section{Introduction}

\section{Background}

A rapid population growth is a burden on the resources of many developing countries. Unregulated fertility, which contributes to such situations, compromises the economic development and political stability of these countries. Therefore, many countries consider limiting population growth as an important component of their overall developmental goal to improve living standards and the quality of life of the people. This strategy is now enhanced by the availability of effective modern contraceptive methods since the 1960s.

Despite widespread adoption of family planning in the developing world, contraceptive use is still very low in much of sub-Saharan Africa and in other regions where women are very poor, uneducated and have limited access to quality family planning services. Sub-Saharan Africa has the highest level of unmet need-about one-fifth of women there do not want to become pregnant, yet use no contraceptive method.

The Millennium Development Goals, adopted by the United Nations in 2000, require member countries to achieve a set of goals, of which Goal 5 is to improve maternal healthy, reducing three quarters of the ratio of women dying in childbirth by 2015. In all these programs, modern contraception plays a central role in the strategies to achieve the goals set.

In Ethiopia family planning was initiated four decades back. However, even after four decades, family planning use is among the lowest in Africa (8\%) and unmet need for family planning is very high (34\%) [1]. Ethiopia is a typical example of a high fertility country [2]. Its current total fertility rate is estimated about 5.4 which is the predicted number of children a woman will have over her reproductive age. During the period 1990 to 2005 Ethiopia's total fertility rate declined by about one child and the use of contraceptives tripled from 5 percent to 15 percent, with most of the increase coming from modern methods, especially pill and injectables [3].

\section{Statement of the problem}

Despite the overall high knowledge of women about modern contraceptive methods, contraceptive use is relatively low in Ethiopia.
According to the data from DHS 2005, awareness of women in reproductive ages of at least one modern contraceptive method is as high as 88 percent, whereas for currently married accounts it is 87 percent. The current use of modern contraceptives is only 14 percent among married women which are totally dominated by short term methods such as pill but long term methods such as injectables, intrauterine device (IUD) and implants accounted for less than 1 percent and only 0.3 and 0.2 percent of women gave unavailability and high price, respectively as the reason for not using contraception. Therefore, barriers to the use of modern contraceptive methods need further study.

\section{Objective}

General objective: The main objective of this study has been to identify factors influencing modern contraceptive methods usage among married women of reproductive age (15-49 years) in Hawassa city, using Bayesian regression analyses.

\section{Specific objectives}

- To identify the influences of demographic and socioeconomic variables on modern contraception method usage among married women of reproductive age.

- To describe the prevalence of modern contraceptives usage among married women of reproductive age.

- To determine whether government family program has an influence on modern contraceptive usage among married women of reproductive ages.

*Corresponding author: Kiros GH, Haramaya University, Haramaya, Ethiopia, Tel: 0912116798; E-mail: Haymanot.kiros20@gmail.com

Received September 12, 2016; Accepted January 03, 2017; Published January 09, 2017

Citation: Kiros GH (2017) Bayesian Regression Analysis of Correlates of Modern Contraceptive Method Usage: A Case Study in Hawassa City, Ethiopia. J Biom Biostat 8: 330. doi:10.4172/2155-6180.1000330

Copyright: (c) 2017 Kiros GH. This is an open-access article distributed under the terms of the Creative Commons Attribution License, which permits unrestricted use, distribution, and reproduction in any medium, provided the original author and source are credited. 


\section{Methodology}

\section{Sampling design and procedures}

Stratified sampling was employed for this study as sampling design, with households as the sampling units. The sampling frame (or the list of the group of the households) was stratified in seven sub-cities (or strata), by taking awareness as the base for the stratification. Households within strata were selected by using random number method.

\section{Data and study design}

This study was cross sectional study. The data were obtained through face-to-face interviews from married women of reproductive age (15-49 years old) by administering a structured questionnaire. However, pregnant women, and women with a chronic physical or mental illness were ineligible. Using stratified random sampling technique, 990 households were selected from the total of 24,178.

\section{Variables in the study}

Dependent variable: The dependent variable used in this study was modern contraceptive usage which is dichotomized as non-user and user.

Independent variables: Independent Variables are: Age of the respondent, Religion of the respondent, Number of children, Desire for more children, Education level, Husband's education level, Husband's Occupation, Monthly income, Occupation, Monthly income, Husband's monthly income, Family planning field workers visit, Frequency of following radio program, Frequency of watching television, Source of information, Number of known method types, Experience on modern contraceptive Use, Husband's encouragement, Availability of service in near place and Service provider

\section{Statistical methods of analysis}

The dependent variable considered in the study was dichotomous. Thus, to examine the net effect of the predictors on the response variable, that is modern contraceptive usage (non-user $=0$, user $=1$ ), Bayesian logistic regression analysis method was used.

\begin{tabular}{|c|c|c|c|}
\hline \multicolumn{2}{|c|}{ Characteristics } & Count & Percentage (\%) \\
\hline \multirow{2}{*}{ Modern contraceptive usage } & User & 573 & 57.9 \\
\cline { 2 - 4 } & Non user & 417 & 42.1 \\
\hline \multirow{2}{*}{ Short term methods user } & Pill & 138 & 93.9 \\
\cline { 2 - 4 } & Lactational Amenorrea & 6 & 4.1 \\
\cline { 2 - 4 } & Condom & 3 & 2 \\
\hline \multirow{2}{*}{ Long term methods user } & Injectables & 350 & 82.2 \\
\cline { 2 - 4 } & Implant & 61 & 14.3 \\
\cline { 2 - 4 } & Intrauterine Devices & 15 & 3.5 \\
\hline
\end{tabular}

Table 1: Characteristics of 990 married women of reproductive age (15-49 years old) on modern contraceptive usage (Hawassa city).

\section{Results and Discussion}

\section{Descriptive analysis}

The information or the data used for the study were obtained from 990 married women of reproductive age (15-49 years) in Hawassa city. The result in Table 1 shows, out of 990 married women of reproductive ages included in the study, about $57.9 \%$ (573) were using one of the modern contraception methods (Table 1).

\section{Bayesian logistic regression analysis for modern contraceptive usage}

Bayesian method gives estimates of parameters by sampling them from their posterior distributions through a Markov Chain Monte Carlo (MCMC) method. This approach was employed to model modern contraceptive usage among married women of reproductive ages. Gibbs sampler algorithm with three different initial values was implemented in this study and 10000 MCMC samples were considered for burn-in after 20000 iterations. The convergence of Markov chain to its stationary or posterior distribution was checked by Time series plot, Density plot, Gelman-Rubin Statistics and comparing the Monte Carlo error (MC error) to its posterior standard errors.

Time series plot: When convergence is achieved the three chains will mix together. In Figure 1 the values on the Y-axis indicate estimates of parameters and values on the $\mathrm{X}$-axis show the number of iterations.

Gelman-Rubin statistics: This test compares the variances within and between the chains. In Figure 2, the lower two lines are stable and the upper line converges to 1 , which imply that the chain has converged to its target distribution [4].

Density plot: The plot on Figure 3 shows that the coefficients for most of the independent variables were normally distributed. Thus, this indicates that the Markov chain has attained its posterior distribution.

However, in addition to the above graphical methods of checking convergence of the chain to its posterior distribution, the Monte Carlo standard error of the posterior mean (which is an estimate of the difference between the estimate of the posterior mean for each parameter and the true posterior mean) is another way of assessing the accuracy of the posterior estimates. The simulation should be run until the Monte Carlo error for each parameter of interest is less than $5 \%$ the sample standard deviation. The Monte Carlo error (MC error), odds ratio $(\operatorname{Exp}(\hat{\beta}))$, sample standard deviation and $95 \%$ confidence intervals for the estimates are reported in Table 2.

The relationship between modern contraceptive usage and the age of the respondent was found statistically significant. The study revealed that being modern contraceptive user for women in age group 25-34 and $35-44$ were 0.171 and 0.166 times less likely than who were in

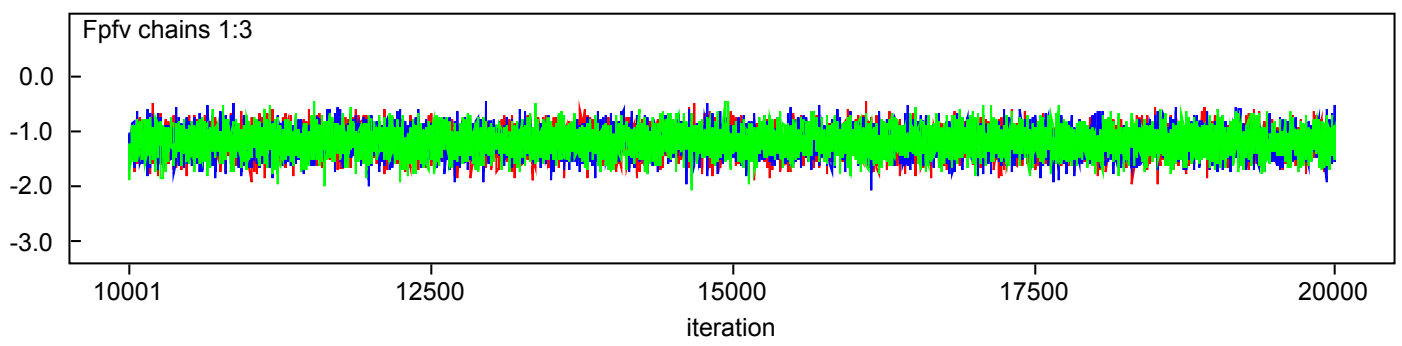

Figure 1: Time series plot for convergence of coefficient for family planning field workers visit (FPFV). 
Citation: Kiros GH (2017) Bayesian Regression Analysis of Correlates of Modern Contraceptive Method Usage: A Case Study in Hawassa City, Ethiopia. J Biom Biostat 8: 330. doi:10.4172/2155-6180.1000330

Page 3 of 4

age group 15-24, respectively. This implies that as the age of woman increases the probability of being modern contraceptive user decreases. Number of children was also a statistically significant predictor. Women with number of children between 1-2 and 3-4 children were 18.011 and 11.681 times more likely to use modern contraception method than those without children (Table 2).

Regarding women's education level, the study indicated that women with primary education level were found more probable to use modern contraception. The odds of being modern contraceptive users

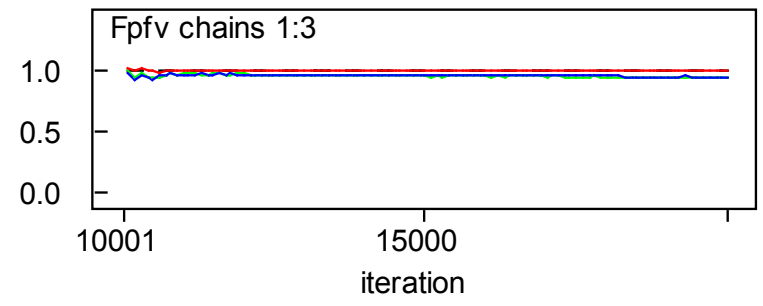

Figure 2: Gelman-rubin statistics for convergence of coefficient for family planning field workers visit (FPFV).

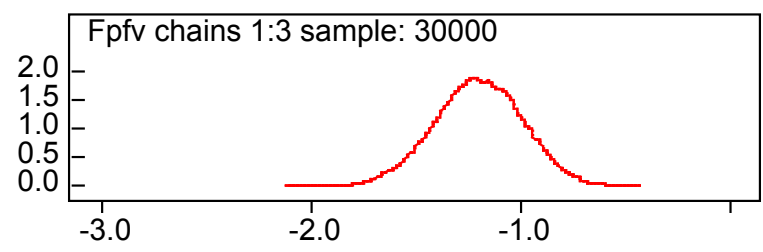

Figure 3: Density plot for convergence of coefficient of family planning field workers visit (FPFV) for women with primary education level were 2.442 times higher than illiterates. In addition, women's occupation was one of the predictors that had statistically significant relationship with modern contraception usage. Women who were working in private organization were 3.927 times more likely to use modern contraceptive than house wives.

The relationship between modern contraceptive usage and monthly income of women was statistically significant. Women earning $>=1000$ birr monthly were 0.159 times less likely to use modern contraception than women without monthly income. This suggests that, as women's monthly income gets higher, the chance to be modern contraception user becomes lower. Family Planning Field Workers Visit was among those statistically significant variables. The result reveals that women visited by family Planning Field Workers were more probable to use modern contraceptive. Being modern contraceptive user for women who were not visited by family planning field workers was 0.301 times less likely than those who were visited

\section{Discussion on modern contraceptive usage}

The Bayesian logistic regression analysis result revealed that the age of the respondent had statistically significant effect on modern contraceptive usage among married women of reproductive ages. The finding indicated that modern contraceptive usage was lower for women in age group 25-34 and 35-44. That is, as the age of married women increases the chance of being modern contraceptive user decreases. This result is consistent with earlier studies by Klein [5] and Dang [6] which indicated that women at higher ages categories were less likely to use modern contraception. Adanu et al. [7] found that younger women of prime reproductive age were significantly more likely to use modern methods than older.

Number of children had significant impact on modern contraceptive usage among currently married women. Women with 1-2 and 3-4 children were more likely to use modern contraceptive methods than

\begin{tabular}{|c|c|c|c|c|c|c|c|}
\hline \multirow[t]{2}{*}{ Node } & \multirow[t]{2}{*}{ Categories } & \multirow[t]{2}{*}{ Mean $(\hat{\beta})$} & \multirow[t]{2}{*}{$\operatorname{Exp}(\hat{\beta})$} & \multirow[t]{2}{*}{$\operatorname{S.E}(\hat{\beta})$} & \multirow[t]{2}{*}{ MC Error } & \multicolumn{2}{|c|}{$95 \% \mathrm{Cl}(\hat{\beta})$} \\
\hline & & & & & & Lower & Upper \\
\hline \multirow[t]{3}{*}{ Age } & 15-24 (Ref) & & & & & & \\
\hline & $25-34$ & $-1.764^{*}$ & 0.171 & 0.3071 & 0.00549 & -2.378 & -1.178 \\
\hline & $35-44$ & $-1.795^{\star}$ & 0.166 & 0.3833 & 0.00684 & -2.548 & -1.053 \\
\hline \multirow{3}{*}{ Number of Child } & No child(Ref) & & & & & & \\
\hline & 1-2 children & $2.891^{*}$ & 18.01 & 0.3767 & 0.00891 & 2.158 & 3.644 \\
\hline & 3-4 children & $2.458^{*}$ & 11.68 & 0.4159 & 0.00935 & 1.649 & 3.286 \\
\hline \multirow[t]{2}{*}{ Education Level } & Illiterate(Ref) & & & & & & \\
\hline & Primary & $0.8927^{*}$ & 2.442 & 0.3801 & 0.00963 & 0.1403 & 1.641 \\
\hline \multirow[t]{2}{*}{ Occupation } & House wife(Ref) & & & & & & \\
\hline & Private organization & $1.368^{*}$ & 3.927 & 0.6735 & 0.01263 & 0.07598 & 2.724 \\
\hline \multirow[t]{2}{*}{ Monthly Income } & None(Ref) & & & & & & \\
\hline & $\geq 1000$ Birr & $-1.842^{*}$ & 0.159 & 0.6054 & 0.01356 & -3.049 & -0.6541 \\
\hline \multirow[t]{2}{*}{ Field Workers Visit } & Yes (Ref) & & & & & & \\
\hline & No & $-1.2^{*}$ & 0.301 & 0.2113 & 0.00236 & -1.624 & -0.7933 \\
\hline \multirow{2}{*}{$\begin{array}{l}\text { Frequency of Following } \\
\text { Radio Program }\end{array}$} & Almost every day(Ref) & & & & & & \\
\hline & Not at all & $-1.326^{*}$ & 0.26 & 0.4279 & 0.0060 & -2.506 & -0.219 \\
\hline \multirow[t]{2}{*}{ Source of Information } & Media (Ref) & & & & & & \\
\hline & Family planning field workers & $-1.255^{*}$ & 0.285 & 0.3059 & 0.00417 & -1.863 & -0.6607 \\
\hline \multirow{2}{*}{$\begin{array}{l}\text { Experience on modern } \\
\text { contraceptive usage }\end{array}$} & Yes (Ref) & & & & & & \\
\hline & No & $-3.14^{*}$ & 0.043 & 0.3117 & 0.00419 & -3.77 & -2.548 \\
\hline \multirow[t]{2}{*}{ Husband's encouragement } & Yes (Ref) & & & & & & \\
\hline & No & $-1.469^{*}$ & 0.23 & 0.2728 & 0.00261 & -2.009 & -0.9387 \\
\hline
\end{tabular}

Ref: Reference category, *significant at $5 \%$ level of significance

Table 2: Posterior parameter estimates for Bayesian Logistic Regression model (Hawassa city, 2011) 
Citation: Kiros GH (2017) Bayesian Regression Analysis of Correlates of Modern Contraceptive Method Usage: A Case Study in Hawassa City, Ethiopia. J Biom Biostat 8: 330. doi:10.4172/2155-6180.1000330

Page 4 of 4

women without child. This result is in agreement with a study by Gupta, et al. [8] and Irja Nelago [9] concluded that women with at least two or more living children were likely to be more interested in limiting child birth as compared to childless women.

In addition, women's education level was found statistically significant predictor. The odds of being modern contraceptive user were higher for women with primary education level than uneducated women. This finding was in agreement with studies by Islam and Mahmud [10], which revealed that the practice of modern methods was more prevalent among women with primary education. It is possible that the higher educated women are more informed about various modern methods and their side effects, which influence them to use traditional methods.

The result revealed that women engaged in private organization were more likely to use modern contraception method than who were not working (house wives). This finding is similar to many studies such as Shiparo and Tambashe [11], Shrestha [12], Govindasamy and Malhotra [13]. Moreover, the monthly income of women had significant effect on modern contraceptive usage. This study indicated that women with higher monthly incomes were less likely to use modern contraception methods than who were without monthly incomes. This result is not consistent with Ali et al. [14], Fikree et al. [15] who concluded the bargaining power and higher autonomy of economically active women resulted into higher likelihood of contraceptive use among them.

Family planning field workers visit had significant impact on modern contraceptive usage among married women. In this study women who were not visited by family planning field workers were less likely to use modern contraceptive than those who were visited. This finding is in line with earlier studies by Rana [16] which indicated that women who were visited by family planning workers were more likely to use contraception than those who were never visited.

\section{Conclusions}

The main purpose of this study was identifying the determinant factors of modern contraceptive usage among married women of reproductive ages (15-49 years old) in Hawassa city. In order to meet the objectives of the study, the Bayesian logistic regression approach was adopted.

A total of 990 married women of reproductive age were considered in the study, of which about $57.9 \%$ were modern contraception methods users. Modern contraceptive usage of married women of reproductive age was found to be significantly associated with most of the predictor variables included in the study. The Bayesian logistic regression analysis revealed that women aged between 15-24, with number of children 1-2 and 3-4, with primary education level, who were private organization workers, who had no monthly income, who were visited by family planning field workers, who were following radio program almost every day, who had husbands' support, who had experience on modern contraceptive usage and those who were getting information about modern contraceptive methods from media were more likely to practice modern contraceptive methods than their counter parts.

\section{References}

1. Amaha H, Fikre E (2006) Influence of women's autonomy on couple's contraception use in Jimma town. Ethiop J Health Dev 20: 145-151.

2. Population Reference Bureau (2004) World Population Data Sheet.

3. Central Statistical Authority (2006) Addis Ababa Ethiopia 41-91.

4. Brooks SP, Roberts GO (1998) Convergence Assessment Techniques for Markov chain Monte Carlo. Statist Comput 8: 319-335.

5. Klein J, Sauer MV (2001) Assessing fertility in women of advanced reproductive Age. Obstetric Gynecology 185: 758-770.

6. Dang A (1995) Differential in contraceptive use and method choice in Vietnam International Family planning perspectives 21: 2-5.

7. Adanu RMK, Seffah JD, Hill AG, Darko R, Duda RB, et al. (2009) Contraceptive Use by Women in Accra, Ghana: Results from the 2003 Accra Women's Health Survey. Afr J Reprod Health 13: 123-133.

8. Gupta N (2003) Associations of Mass Media Exposure with Family Planning attitudes and Practice in Uganda. Studies in Family Planning, 34: 19-31.

9. Irja N (2007) Contraceptive use among young women in Namibia, Determinants and policy implication. DPhil thesis sociology (Demography).

10. Islam M, Muhmud M (1995) Contraception among adolescents in Bangladesh. Asian-pacific population Journal 10: 21-38.

11. Shiparo D, Tambashe BO (1998) The Impact of Women's Employment and education on Contraceptive Use and Abortion in Kinshasa, Zaire. Studies in family Planning 25: 96-110.

12. Shrestha D (2000) Determinants of Current Contraceptive Use among Nepalese Women. Nepal Population and Development Journal, Ministry of Population and Environment, Nepal.

13. Govindasamy P, Malhotra A (1996) Women's Position and Family Planning in Egypt. Studies in Family Planning 27: 328-340.

14. Ali S, Rozi S, Mahmood MA (2004) Prevalence and factors associated with practice of modern contraceptive method among currently married women in district Naushahro Feroze. J Pak Med Ass 54: 461-465.

15. Fikree FF, Khan A, Kadir MM, Sajan F, Rahbar MH (2001) What Influences contraceptive Use among Young Women in Urban Squatter Settlements of Karachi, Pakistan. International Family Planning Perspectives 27: 130-136.

16. Rana SB (2002) Factors influencing contraceptive Method Choice in Nepal Thesis submitted to IPSR, Mahidol University, Thailand. 